Original Articles

\title{
Descriptive study of the psychosocial and physical environments of school in relation to violence among adolescents in the Gampaha District of Sri Lanka
}

\author{
*Monika Priyadarshani Wijeratne ${ }^{1}$, Rohini Seneviratne ${ }^{2}$, Nalika Gunawardena ${ }^{2}$, Truls Østbye ${ }^{3}$, \\ Catherine Lynch ${ }^{4}$
}

Sri Lanka Journal of Child Health, 2015; 44(3): 138-142

\begin{abstract}
Introduction: Adolescents spend a considerable proportion of their time in school and the physical and psychosocial dimensions of schools are important for their wellbeing.
\end{abstract}

Objective: To assess the psychosocial and physical environments of schools for factors that promote or prevent peer violence among adolescents in the Gampaha District of Sri Lanka.

Methods: A cross sectional study was carried out in 28 schools in the Gampaha District, Sri Lanka. A locally developed and validated checklist was used to obtain information through observation, by perusing school records and by interviewing teachers of grades 8-10 and school principals.

Results: Only $32 \%$ of schools had a code of conduct or policy on violence among students and $44 \%$ stated that school will not tolerate bullying. None had specified procedures to deal with victims of violence. Only $21 \%$ of schools had a policy discouraging physical punishments by teachers. Of the schools $39 \%$ had abandoned classrooms or buildings, $28 \%$ had dark places and $43 \%$ had other places which may facilitate violence.

Conclusions: The psychosocial and physical environments of schools in the Gampaha district are unsatisfactory regarding prevention of peer violence among adolescents in Sri Lanka.

Consultant Community Physician, Ministry of
Health, Sri Lanka, ${ }^{2}$ Professor in Community
Medicine, Faculty of Medicine, University of
Colombo, Sri Lanka, ${ }^{3}$ Professor, Duke Global
Health Institute, Duke University and Health
Services and Systems Research, Duke-NUS,
Singapore, ${ }^{4}$ Assistant Professor of Surgery and
Global Health, Duke Division of Emergency
Medicine, Department of Surgery, Duke Global
Health Institute, Duke University, Durham
*Correspondence: monika.wijeratne@gmail.com

(Received on 01 August 2014: Accepted after revision on 19 August 2014)
(Key words: Adolescents, violence, school, physical environment, psychosocial environment)

\section{Introduction}

"The children of today are the adults of tomorrow. They deserve to inherit a safer, fairer and healthier world. There is no task more important than safeguarding their environment"1. The school environment consists of both psychosocial and physical components. Psychosocial environment of a school depends to a large extent on the policies and attitudes of the staff and the way schools are organized. A school's environment can enhance social and emotional wellbeing and learning when it is warm and friendly. A child-friendly school rewards learning and promotes cooperation rather than competition, facilitates supportive, open communications and views the provision of creative opportunities as important. Such a school prevents physical punishment, bullying, harassment and violence. School policies should promote nonviolent interaction on the playground and in class and among staff and students. Furthermore, school policies should promote the rights of male and female students through equal opportunities and democratic procedures ${ }^{2}$. Modifications to the physical environment to remove features that promote violence are also important for physical as well as psychosocial wellbeing of children. Further, features that discourage violence could be easily included in the school environment. Thus, the school environment is modifiable to prevent violence and collecting ground level information is necessary to provide recommendations for school based violence prevention programmes to increase the school's capacity to be supportive and caring toward students. Although researchers ${ }^{3,4,5}$ have identified "violence in schools" as a major public health problem, the psychosocial environment in schools in relation to peer violence has not been studied much in Sri Lanka.

\section{Objective}

To assess the psychosocial and physical environments of schools for factors that promote or 
Descriptive study of the psychosocial and physical environments of school in relation to violence among adolescents in the Gampaha District of Sri Lanka Sri Lanka Journal of Child Health, 2015; 44(3): 138-142

prevent peer violence among adolescents in the Gampaha District of Sri Lanka.

\section{Method}

A descriptive cross-sectional study was conducted from July to December, 2010 in Gampaha district schools identified by a two-stage cluster sampling technique. All 4 educational zones in the district were included in study. Each educational zone is divided into 3 educational divisions. In the first stage of sampling, 4 educational divisions, one from each educational zone were randomly selected. In the 2nd stage of sampling, 28 schools were randomly selected, 7 from each educational division. The physical environments were assessed and teachers of grades 8-10 and school principals of the 28 schools were interviewed.

Data was collected based on a checklist developed based on the Psycho-Social Environment (PSE) profile questionnaire developed by the World Health Organisation (WHO $)^{2}$ and further adapted for Sri Lanka by experts in the field of school health. It assesses policies, procedures and features of physical environment in the school setting. The checklist was pre-tested in 2 schools in Colombo district for feasibility and appropriateness. The checklist was completed by the principal investigator (first author) based on observation, by perusing school records and by interviewing teachers of grades 8, 9 and 10 and school principals. Data entry and descriptive analysis was carried out using the Statistical Package for Social Sciences (SPSS) Version 16. Items in the checklist included only two possible response categories (yes or no).

Ethical clearance was obtained from the Ethical Committee of the Faculty of Medicine, Colombo, Sri Lanka. Administrative clearance for data collection was obtained from the Director of Education- Western Province, Zonal Directors and Principals of all selected schools.

\section{Results}

Out of the 28 schools only $9(32.1 \%)$ had a code of conduct or a school policy on violence. Of the 9 schools with a code of conduct only 2 had updated it within the last 5 years. Three $(33.3 \%)$ schools had provided each student with a written copy of the code of conduct or school policy and $5(55.5 \%)$ had provided a copy of the code of conduct to newcomers. Four (44.4\%) schools had displayed a copy of code of conduct within the school $2(50 \%)$ of which were displayed in a location only accessible to the staff while the other $2(50 \%)$ were accessible to students, staff and visitors. Out of 9 schools which had a code of conduct, 2 (22.2\%) recognized the good behaviour of students, while 4 (44.4\%) had a no-tolerance bullying clause and 6 $(66.7 \%)$ stated that physical violence on school premises would not be tolerated. None of the schools had specified procedures dealing with violence victims and only $4(44.4 \%)$ schools specified procedures dealing with perpetrators of violence. The availability of procedures to deal with problems related to violence is shown in Table 1 while school policies for teachers to prevent violence among students are included in Table 2.

Table 1: Availability of procedures to deal with problems related to violence

\begin{tabular}{|l|c|}
\hline \multicolumn{1}{|c|}{ Variable } & Number (\%) $n=28$ \\
\hline Procedures to assist students who have witnessed violence & $00(00.0)$ \\
\hline Trained school staff for student conflicts mediation & $02(07.1)$ \\
\hline Delineated staff who can be approached by students for conflict mediation & $19(67.9)$ \\
\hline Procedures to prevent newcomers being victims of violence & $13(46.4)$ \\
\hline Procedures to encourage older students to protect new comers from violence & $04(14.3)$ \\
\hline Procedures to encourage teachers to protect newcomers from violence & $04(14.3)$ \\
\hline
\end{tabular}

Table 2: Policies in school for teachers related to prevention of violence among students

\begin{tabular}{|l|c|}
\hline \multicolumn{1}{|c|}{ Variable } & Number (\%) $n=28$ \\
\hline A policy discouraging physical punishments by teachers & $06(21.4)$ \\
\hline A policy encouraging teachers to support violence victims & $03(10.7)$ \\
\hline $\begin{array}{l}\text { A policy to support the inclusion of 'loners' or those who are recognized as } \\
\text { 'different' in school activities }\end{array}$ & $04(14.3)$ \\
\hline $\begin{array}{l}\text { A policy of encouraging teachers to gain new knowledge and skills to } \\
\text { maintain safety and security within the school }\end{array}$ & $00(00.0)$ \\
\hline
\end{tabular}

In total, only $4(14.3 \%)$ schools were keeping records of violent incidents among students and only $2(7.1 \%)$ schools were recording injuries reported by students and staff as result of student violence. Opportunities for other sectors or personnel to get involved in school administrative procedures are shown in Table 3. 
Descriptive study of the psychosocial and physical environments of school in relation to violence among adolescents in the Gampaha District of Sri Lanka Sri Lanka Journal of Child Health, 2015; 44(3): 138-142

Table 3: Information regarding involvement of other personnel in school administrative activities

\begin{tabular}{|l|c|}
\hline \multicolumn{1}{|c|}{ Variable } & Number (\%) $n=28$ \\
\hline Parents are involved in formulating policies/ regulations regarding student behaviours & $10(35.7)$ \\
\hline Parents are involved in school governance & $02(07.1)$ \\
\hline Primary care health staff are involved in school health club & $18(64.3)$ \\
\hline Primary care health staff are involved in violence prevention in the school & $00(00.0)$ \\
\hline
\end{tabular}

Discussions with school authorities revealed that in $18(64.3 \%)$ schools, primary care health staff was involved in the functioning of school health club but they have not been involved in violence prevention activities in any school. Four (14.3\%) schools had displayed posters or wall paintings on school premises promoting non-violent behaviour. School premises were examined for the existence of places facilitating violence within the school, and it was observed that $11(39.3 \%)$ schools had abandoned classrooms or buildings, $8(28.6 \%)$ schools had dark places and $12(42.9 \%)$ schools had other places which may facilitate violence. When discussing with school authorities, the maintenance of the physical school environment to prevention potential locations conducive to violence, only $2(7.1 \%)$ schools had done so.

\section{Discussion}

The present study revealed that most schools have not taken advantage of its psychosocial and physical environments as tools to prevent violence among students. Student behaviour related to violence has not been taken up as a policy issue by schools. Even the 9 (32.1\%) schools which had some policy regarding student behaviour had not mentioned policies related to bullying and physical harassment among students. Unavailability of mechanisms/procedures to deal with violent incidents discourages victims and witnesses of violence to report them. Record keeping in schools regarding occurrence of violence was very poor. This further reflects the fact that schools may lack interest of utilizing easy system of monitoring occurrence of violence. This can be also viewed as a lost opportunity to identify the extent of the problem of violence and its consequences.

Out of those schools that had some policy referring to student's behaviour, only two had updated the code of conduct or policy for the past five years, a majority had not attempted to make students and parents aware on these policies and nearly half of schools had not given a copy of it to newcomers, also possibly indicating lack of interest among the school authorities to use the policies to modify the psychosocial environment of the school. As expressed by teachers, the only goal of the school supervisory system of education sector in the country is to assess completion of the syllabus by the teachers. No attention is given to school performance related to prevention of violence. In the teachers' view even parents concentrate on teaching subject matters without much interest in the child's behaviour. Teachers were not encouraged by the schools to pay attention to preventing violence. This was evident when the teachers said that they do understand problems of violence among adolescent students, and they are aware of how victims of violence suffer, but they do not have time to attend to the students needs. According to the teachers, there is immense pressure on them and on the students due to the current education system, so there is less time for teachers to pay attention to prevent violence.

These findings are supported by the national survey among adolescents in Sri Lanka, conducted by UNICEF in 2004. The number of adolescents who felt pressured by the expectations of their parents and teachers for improved academic performance rose from $29 \%$ among early adolescents (10-13 year old) to $46 \%$ among late adolescents (14-19 year old $)^{6}$. Another piece of evidence that may indicate lack of interest among school systems to get the teachers involved in prevention of violence among students was that only two schools had trained staff members to mediate when conflicts among students occurred. No school had offered opportunity for the teachers to gain new knowledge and skills to maintain safety and security within the school.

Almost $80 \%$ of schools (22 schools) had no policy discouraging physical punishment by teachers. Sri Lankan researchers have identified the high frequency of corporal punishment by school teachers/principal as a risk factor of violence among students ${ }^{3,4}$. Association of corporal punishment with violent behaviour of adolescents is supported by studies carried out in other countries as well. A study from Alexandria in 1999 of 2170 adolescents (mean age 14.6 years) reported that corporal punishment in school increases the risk of violence 2.7 times among adolescents ${ }^{7}$. However, corporal punishment is still culturally accepted by many teachers in Sri Lanka. They identified it as a method of disciplining students, even as a mean to prevent violence ${ }^{3}$.

Only $10(35.7 \%)$ schools had parental involvement in formulating policies and regulations regarding student behaviour and only $2(7.1 \%)$ schools had parental involvement in the governance of school. Teachers were of the view that many parents are 
not ready to support school activities. Parental involvement in policy development is usually considered a key component of the concept of health promoting school $^{3}$. Eighteen (64.3\%) schools had functioning school health clubs with involvement of primary health care staff. This indicates the acceptance of the primary health care service by the school system. However, primary health care staff has not yet become involved in prevention of violence in any of the schools. Existing primary health care service was identified as a resource for conducting violence prevention programmes in schools.

While the physical environment of many schools had features which promote violence, only a few (four) schools had certain features which discourage violence. This is another area that should be addressed by school authorities.

\section{Conclusions}

The psychosocial and physical environments of schools in the Gampaha district are unsatisfactory regarding prevention of peer violence among adolescents in Sri Lanka.

\section{Implications for school health}

A positive psychosocial environment at school would promote the mental health and wellbeing of adolescents. Further it affects the quality of their education. A sense of connectedness, good communication, and perceptions of caring adult has been shown to be related with a wide range of favourable mental health outcome ${ }^{2}$. Violence, abuse, harassment, and discrimination among students as well as between staff and students are barriers for school participation, even to school attendance. By implementing policies and practices that could create a caring school community that is characterized by cooperation, effective communication, appreciation of differences, and shared decision making, could create healthy school climate. A Health-Promoting School can create student and staff conduct and discipline codes regarding violence and aggression. School policies and practices should advance relations between adolescent students that are respectful, non abusive and non-discriminatory. Policies should also enhance teacher-student respect and discrimination. In instances of abuse, violence, harassment or discrimination among students, between staff and students should be condemned openly to promote appropriate social norms ${ }^{8}$. Discipline does not drive from rules, punishments, and external control. It is also learned from reinforcement and by consequences which are fair, firm, and clearly communicated.
Physical environment of school also plays a crucial role in either facilitating or discouraging violence. Facilitative locations such as dark places, abandoned class rooms or abandoned buildings, etc within the school premises could encourage violence among students. Some strategies that ensure the school's appearance, lay out and facilities that discourage violence are, school cleanups (painting parties), lightening dark areas in school premises to discourage violence, making emergency exits more visible, murals and posters with non-violent messages, public announcements supporting non-violent, school safety plans with parents and community inputs, providing safe passages for students on their way to and from school, providing student identity cards to restrict outsiders from entering school grounds and weapon detecting systems etc ${ }^{8}$.

The school environment is easily changeable in order to prevent violence and collecting ground level information is a must to provide recommendations for school based violence prevention programmes on increasing the school's capacity to be supportive and caring toward students. The school authorities should be educated about evidence-based strategies to modify the psychosocial and physical environments of the schools to prevent violence among adolescents. Ministry of Education needs to formulate and disseminate schools policies on prevention of student involvement in violence. Parents and primary health care staff should also be engaged to achieve health promoting schools.

\section{Limitations of the study}

This study was a part of a descriptive cross sectional study carried out in Gampaha district schools to assess peer violence among adolescents. Data presented in this paper are an assessment of the environments of the schools, selected to recruit adolescent participants for above mentioned study. Thus the study sample was limited to the schools in Gampaha district and findings must therefore be generalized to the rest of the country with caution.

\section{Acknowledgements}

We convey our gratitude to all experts, teachers, parents and all those who reviewed the questionnaire and made valuable suggestions. We are also grateful for the extensive co-operation provided by the zonal directors, school principals, teachers, parents and students. Our gratitude further extends to all the study participants who generously participated in this study. 
Descriptive study of the psychosocial and physical environments of school in relation to violence among adolescents in the Gampaha District of Sri Lanka Sri Lanka Journal of Child Health, 2015; 44(3): 138-142

\section{References}

1. World Health Day, 2003. Shape the Future of life: Healthy environments for children. Geneva, Switzerland: World Health Organization. Available from: http://www.prb.org/Publications/Articles/2 003/WorldHealthDay2003AFocusonChild rensEnvironmentalHealth.aspx

2. WHO, 2003. Creating an Environment for Emotional and Social Well-Being: Information Series on School HealthDocumet 10. Geneva, Switzerland: World Health Organization. Available from: http://www.who.int/school_youth_health/ media/en/sch_childfriendly_03_ve-pdf

3. Wijeratne MP. 2012. Interpersonal violence among 13-15 year old schooling adolescents in district of Gampaha. MD Thesis. Colombo: Postgraduate Institute of Medicine, University of Colombo.

4. Hewamalage AP. 2010. School violence among grade 10 students in Kesbewa education division. MSc Thesis. Colombo: Post Graduate Institute of Medicine, University of Colombo.

5. Wijesekera KL. 2003. Selected factors associated with physical violence and immediate consequences of violent incidents among advanced level students in Kaluthara Educational division, Dissertation (MSc-Community Medicine). MSc Thesis. Colombo: Post Graduate Institute of Medicine, University of Colombo PGIM, University of Colombo.
6. UNICEF, 2004. National Survey on Emerging Issues among Adolescents in Sri Lanka. National Survey Report. Colombo, Sri Lanka: UNICEF Ministry of Health. Available from:

http://www.unicef.org/srilanka/Full_Repor t.pdf

7. Youssef RM, Attia MS, Kamel MI.. Violence among schoolchildren in Alexandria. Eastern Mediterranean Health Journal 1999; 5(2), 282-98. Available from: http://applications.emro.who.int/emhj/050 2/EMHJ_1999_5_2_282_298.pdf PMid: 10793805

8. WHO, 1996. The status of schoolhealth. MA, Newton: WHO/HQ HEP Unit, Education development centre World Health Organization. Available from: http://www.who.int/school_youth_health/ media/en/87.pdf 